\title{
Ensino Híbrido Aplicado a Capacitações Profissionais: Um Mapeamento Sistemático da Literatura
}

\author{
Igo J. D. Diniz'1, Apuena V. Gomes ${ }^{1}$ \\ ${ }^{1}$ Instituto Metrópole Digital - Universidade Federal do Rio Grande do Norte (UFRN) \\ 59.078-970 - Natal - RN - Brasil \\ \{igojoven@gmail.com, apuena@gmail.com\}
}

\begin{abstract}
Blended Learning combines pedagogical practices of face-to-face teaching and distance learning, with the aim of improving students performance in both of them. B-learning can be applied in companies, promoting interactive, dynamic and personalized training. This study presents a systematic mapping of the literature (SLM) built in order to understand the state of the art about the theme in Brazil and around the world, by works that approach b-learning as a methodology applied to the process of professional qualification. It was mapped 290 papers, of which, after inclusion and exclusion criteria, were resulted in 11 papers. The selected works were distributed in different levels, areas of study and approaches, permitting to reflect a worldwide reality, as well as a base for future studies.
\end{abstract}

Resumo. O ensino híbrido (EH) combina práticas pedagógicas do ensino presencial e do ensino a distância, com o objetivo de melhorar o desempenho dos alunos em ambos. Pode ser aplicado em empresas, promovendo treinamentos interativos, dinâmicos e personalizados. O presente estudo realiza um mapeamento sistemático da literatura (MSL) afim de entender o estado da arte sobre o tema no Brasil e no mundo, a partir de trabalhos que abordem o EH como metodologia aplicada ao processo de capacitação profissional. Foram mapeados 290 trabalhos que, após critérios de inclusão e exclusão, resultaram em 11. Os trabalhos selecionados estão distribuídos em diferentes níveis, áreas de estudo e abordagens, possibilitando refletir a realidade a nivel mundial, bem como servir de base para estudos futuros.

\section{Introdução}

Atualmente, diante do surgimento e propagação das tecnologias digitais de informação e comunicação (TDIC), e alicerçada com o uso da internet, a sociedade do século XXI vem sofrendo transformações significativas, modificando sua forma de viver e conviver em comunidade. Na educação essas modificações, decorrentes em grande parte da disseminação massiva das tecnologias digitais, promovem novas possibilidades de expressão e comunicação, permitindo outros campos de estudos e pesquisas até então desconhecidos. [DINIZ et, al. 2018]

Segundo Moran (2015, p. 30) "As instituições que implantem modelos, que equilibrem economia e inovação, melhorando os processos gerenciais e acadêmicos, serão vencedoras". O autor indica que as instituições utilizarão o ensino híbrido como modelo predominante de educação, unindo o modelo presencial e o EAD, logo, os cursos presenciais se tornarão semipresenciais (híbridos).

O ensino híbrido combina práticas pedagógicas do ensino presencial e do ensino a distância, com o objetivo de melhorar o desempenho dos alunos em ambos. A parte presencial deve necessariamente contar com a supervisão do professor, valorizar as 
VIII Congresso Brasileiro de Informática na Educação (CBIE 2019)

Anais do XXV Workshop de Informática na Escola (WIE 2019)

interações interpessoais e ser complementar às atividades on-line, proporcionado um processo de ensino e de aprendizagem mais eficiente, interessante e personalizado [VALENTE, 2014].

De acordo com (Horn e Staker, 2015), os cursos híbridos enquadram-se em alguma das quatro modelos principais: Rotação, Flex, À la Carte e Virtual Enriquecido. Por sua vez, o modelo de rotação subdivide-se em: Rotação por estações, Laboratório Rotacional, Sala de aula invertida, Rotação Individual.

Além de ser um grande aliado ao currículo escolar, o ensino híbrido pode amplamente aplicado em empresas, independente do porte ou da área de atuação. A flexibilidade desta modalidade oferece vantagens para aperfeiçoamento profissional, promovendo treinamentos corporativos interativos, dinâmicos e personalizados. A aplicação do b-learning no mundo corporativo traz uma série de benefícios para todos os interessados: maximiza recursos, promove engajamento, reduz custos e impacta de forma positiva a produtividade. [EADBOX, 2017]

Diante deste contexto, buscando entender o estado-da-arte, como parte integrante de uma dissertação de mestrado, este trabalho realiza um Mapeamento Sistemático da Literatura (MSL) acerca do ensino híbrido conexo ao mundo corporativo como metodologia impulsionadora em capacitações.

\section{Mapeamento sistemático da literatura}

Para definir o estado da arte da temática em questão, optou-se pela realização do mapeamento sistemático da literatura, metodologia utilizada em revisões da literatura de forma sistêmica e organizada. Este tipo de estudo tem, em geral, um foco em tópicos de pesquisa nos quais poucas evidências são disponíveis na literatura [KITCHENHAM; CHARTERS, 2007]. O MSL é utilizado quando não é necessário responder com profundidade questões específicas, mas sim uma visão geral mais ampla de determinada área [DERMEVAL; COELHO; BITTENCOURT, 2019].

\subsection{Definição das Questões de Pesquisa}

A realização deste mapeamento sistemático propõe o levantamento e análise de publicações acerca da temática pretendida, para tal, foram elaboradas as seguintes Questões de Pesquisa (QP) foram propostas. A QP principal que norteia este trabalho é: Existem trabalhos publicados que abordam o ensino híbrido como metodologia aplicada no processo de capacitação profissional? Para responder tal questão foram definidas algumas Questões Secundárias: Q1- Quais as características gerais das publicações (nível, origem, área de estudo, ano da publicação, sujeitos da pesquisa) ?; Q2 - Quais: metodologias, recursos (AVA) e modelos de Ensino Híbrido adotados?; Q3 Quais os principais objetivos e resultados alcançados nos trabalhos encontrados? Portanto, propor este mapeamento determinou a possibilidade de identificar o EH como metodologia aplicada ao processo de capacitação profissional a nível mundial, identificar as contribuições desta temática, servindo como base para trabalhos futuros. 
VIII Congresso Brasileiro de Informática na Educação (CBIE 2019)

Anais do XXV Workshop de Informática na Escola (WIE 2019)

\subsection{Processo de busca}

Para identificar o estado da arte da temática abordada neste projeto fez-se necessária a busca por publicações relacionadas ao objeto de pesquisa pretendido nas principais bases de dados de revistas, anais, periódicos e eventos relacionados a temática de tecnologias educacionais, delimitando o período dos últimos 5 anos, correspondido de 2014 a 2018. As bases utilizadas foram os portais da $\mathrm{SciELO}^{1}, \mathrm{CEIE}^{2}\left(\mathrm{RBIE}^{3}, \mathrm{SBIE}^{4}, \mathrm{WIE}^{5}, \mathrm{CBIE}^{6}\right)$, $\mathrm{BDTD}^{7}$ e CAPES ${ }^{8}$, pois indexam várias outras bases, logo, concentram um maior número de publicações.

Para realizar as buscas optou-se pelo método automático de pesquisa no qual é formulada uma string de busca contendo os termos-chave ou descritores e parâmetros desejados para a consulta eletrônica nas bases de dados.

Para elaborar a string primeiramente foi necessário definir os termos-chave relevantes à pesquisa, assim, buscou-se na literatura referente às duas temáticas centrais desta pesquisa (ensino híbrido e capacitação) os termos usuais, seus sinônimos bem como as respectivas traduções para a língua inglesa para que fosse possível ampliar a busca em bases de relevância internacional.

Logo após a definição dos descritores, seguindo a mesma lógica foram elaboradas duas strings de busca, uma para cada idioma de forma personalizada para que retornassem publicações relacionadas a temática pesquisada. Neste momento foi necessário adequar os descritores da string em português, retirar acentuação e cedilha por exemplo para evitar retornos nulos e/ou incorretos. Assim, adequando os descritores e conectores para refinar os retornos da busca chegou-se nos resultados apresentados no Quadro 1:

Quadro 1: Strings de busca por idioma

\begin{tabular}{|c|l|}
\hline Idioma & \multicolumn{1}{|c|}{ String } \\
\hline Português & $\begin{array}{l}\text { ("Ensino Hibrido OR Semipresencial") AND (Capacitacao OR Treinamento OR "Formacao } \\
\text { Continuada" OR "Educacao Continuada" OR "Educacao permanente" OR "Capacitacao em } \\
\text { servico") }\end{array}$ \\
\hline Inglês & $\begin{array}{l}\text { ("blended learning" OR "b-learning") AND ("Training" OR "Continuing Education" OR "In } \\
\text { service") }\end{array}$ \\
\hline
\end{tabular}

Fonte: Elaborado pelos autores

Após realizar as buscas utilizando as strings genéricas percebeu-se que os resultados obtidos na plataforma CAPES não eram condizentes com o esperado, hora nulos, hora apresentando muitos artigos fora da temática desejada. Diante deste contexto, foi necessário realizar as buscas de forma personalizada nessa base utilizando apenas dois

\footnotetext{
${ }^{1}$ Scientific Electronic Library Online

2 Comissão Especial de Informática na Educação - SBC

3 Revista Brasileira de Informática na Educação

4 Simpósio Brasileiro de Informática na Educação

5 Anais do Workshop de Informática na Escola

6 Anais dos Workshops do Congresso Brasileiro de Informática na Educação

${ }^{7}$ Biblioteca Digital Brasileira de Teses e Dissertações

${ }^{8}$ Coordenação de Aperfeiçoamento de Pessoal de Nível Superior
} 
VIII Congresso Brasileiro de Informática na Educação (CBIE 2019)

Anais do XXV Workshop de Informática na Escola (WIE 2019)

descritores combinados por vez, gerando 16 pequenas strings. Por exemplo: ("Blended Learning”AND “Continuing Education”).

Após a realização deste processo personalizado à plataforma CAPES, somado à as buscas com a string genérica nas demais bases, obteve-se o retorno de 163 publicações em português, 127 em inglês, totalizando $\mathbf{2 9 0}$ trabalhos encontrados nas bases de dados acadêmicos pesquisadas, conforme é demonstrado na Tabela 1.

Tabela 1: Publicações encontradas por base de dados

\begin{tabular}{|c|c|c|c|c|c|}
\hline \multirow{2}{*}{ Idioma } & \multicolumn{5}{|c|}{ Base de Dados } \\
\cline { 2 - 5 } & SciELO & CEIE & BTTD & CAPES & \\
\hline PT & 2 & 5 & 147 & 9 & $\mathbf{1 6 3}$ \\
\hline EN & 6 & 0 & 0 & 121 & $\mathbf{1 2 7}$ \\
\hline PT + EN & 8 & 5 & 147 & 130 & $\mathbf{2 9 0}$ \\
\hline
\end{tabular}

\subsection{Critérios de inclusão e exclusão}

Feito o levantamento inicial constatou-se que mesmo utilizando a string de busca combinando os descritores, operadores de pesquisa e filtros necessários, buscando apenas em títulos, resumos e palavras chave a maioria dos artigos encontrados não apresentavam a característica básica pretendida na busca, que é mencionar em algum dos campos supracitados a relação entre ensino híbrido e capacitação ou seus sinônimos/ traduções. Logo, para otimizar a triagem e posterior análise dos trabalhos encontrados, foram estabelecidos critérios de inclusão e exclusão conforme é demonstrado no Quadro 2:

Quadro 2: Critérios de Inclusão e Exclusão

\begin{tabular}{|l|l|c|l|}
\hline \multicolumn{2}{|c|}{ Critério de Inclusão } & \multicolumn{2}{c|}{ Critério de Exclusão } \\
\hline CI-1 & $\begin{array}{l}\text { Trabalhos que atendem aos descritores } \\
\text { de busca utilizados }\end{array}$ & \multirow{2}{*}{ CE-1 } & Trabalhos duplicados \\
\hline CI-2 & $\begin{array}{l}\text { Trabalhos publicados em anais de } \\
\text { eventos, periódicos e revistas }\end{array}$ & $\begin{array}{l}\text { Trabalhos primários, discussões teóricas, } \\
\text { estado da arte, revisões bibliográficas, } \\
\text { sistemáticas }\end{array}$ \\
\cline { 1 - 2 } CI-3 & $\begin{array}{l}\text { Trabalhos publicados nos últimos 5 anos } \\
(2014-2018)\end{array}$ & \multirow{2}{*}{ CE-3 } & $\begin{array}{l}\text { Trabalhos que não tratem da aplicação do } \\
\text { ensino híbrido em processos de } \\
\text { capacitação/treinamentos de forma prática }\end{array}$ \\
\hline CI-4 & Trabalhos revisados por pares ou bancas \\
\cline { 1 - 2 } CI-5 & $\begin{array}{l}\text { Trabalhos que foram escritos em Língua } \\
\text { Inglesa ou em Língua Portuguesa }\end{array}$ &
\end{tabular}

Fonte: Elaborado pelos autores

No universo de 290 publicações, após a aplicação dos critérios de inclusão e exclusão, 275 trabalhos foram eliminados, restando apenas 15 dentro dos critérios. Neste momento percebeu-se que dentre os trabalhos eliminados estavam, sobretudo publicações que tratavam do ensino híbrido ou de capacitações de maneira não relacionada.

Após esta pré-seleção, foi realizada a leitura completa dos 15 trabalhos selecionados, neste momento foram avaliados os seguintes requisitos: título, ano de publicação, origem, instituição responsável pela publicação, localidade, nível da publicação, área de estudo, sujeitos da pesquisa, metodologia, modelo de ensino híbrido utilizado, plataforma ou ambiente virtual de aprendizagem utilizado, objetivos pretendidos e resultados alcançados. Vale ressaltar que esta etapa foi bastante morosa, 
VIII Congresso Brasileiro de Informática na Educação (CBIE 2019)

Anais do XXV Workshop de Informática na Escola (WIE 2019)

pois a maioria das publicações eram dissertações de mestrado e teses de doutorado com grande volume de páginas.

Nesta etapa 4 trabalhos foram eliminados pelo critério (CE-3), pois apesar de aparentemente relatarem em seus resumos, na realidade não se enquadravam dentro deste critério. Ao final deste processo restaram apenas 11 trabalhos dentro dos critérios estabelecidos.

Por questões de organização e com o objetivo de realizar uma análise mais detalhada e dinâmica das publicações, através dos dados coletados foram geradas as tabelas e gráficos que serão analisados e discutidos na próxima na seção de resultados e discussões.

\section{Resultados e discussões}

Quanto ao nível das publicações foram identificados 3 tipos, onde 55\% dos trabalhos são dissertações a nível de mestrado, $27 \%$ são artigos publicados em revista ou periódicos e $18 \%$ são teses de doutorado.

No que se refere a origem das publicações, de acordo com o Gráfico 1, temos $64 \%$ de origem nacional e $36 \%$ de origem internacional. Vale salientar que foi encontrada uma variedade ampla quanto a localidade das publicações internacionais, abrangendo países de quatro dos cinco continentes: americano, africano, asiático e europeu. Assim, havendo representatividade bastante abrangente a nível mundial. Já os trabalhos de origem nacional, se concentravam nas regiões norte, centro-oeste, sobretudo na região sudeste do país, tendo o estado de São Paulo o maior número de trabalhos selecionados.

\section{Gráfico 1: Origem das Publicações}

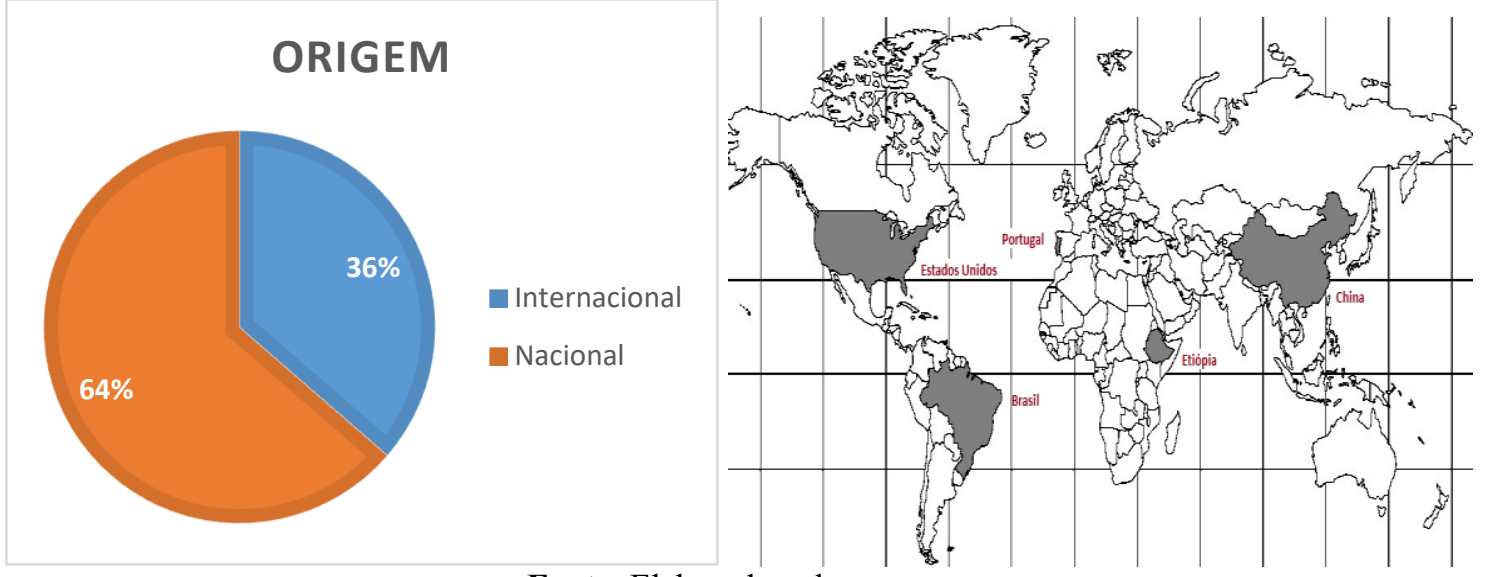

Fonte: Elaborado pelos autores

Quanto a área de estudo, ilustrada no Gráfico 2, as publicações encontradas estão distribuídas da seguinte forma, $46 \%$ na área de educação, $36 \%$ na área de ciências da saúde, $9 \%$ em psicologia e também 9\% em medicina veterinária. Todavia, se considerarmos que psicologia e medicina veterinária são áreas conexas às ciências da saúde teríamos então $54 \%$ das publicações nesta área, percentual superior às publicações na área de educação. Logo é possível afirmar que a temática do ensino híbrido, ligada às tecnologias educacionais e naturalmente relacionada à educação, tem relevância considerável na área de saúde, como metodologia aplicada a capacitações em serviço. 
VIII Congresso Brasileiro de Informática na Educação (CBIE 2019)

Anais do XXV Workshop de Informática na Escola (WIE 2019)

Gráfico 2: Área de estudo das Publicações

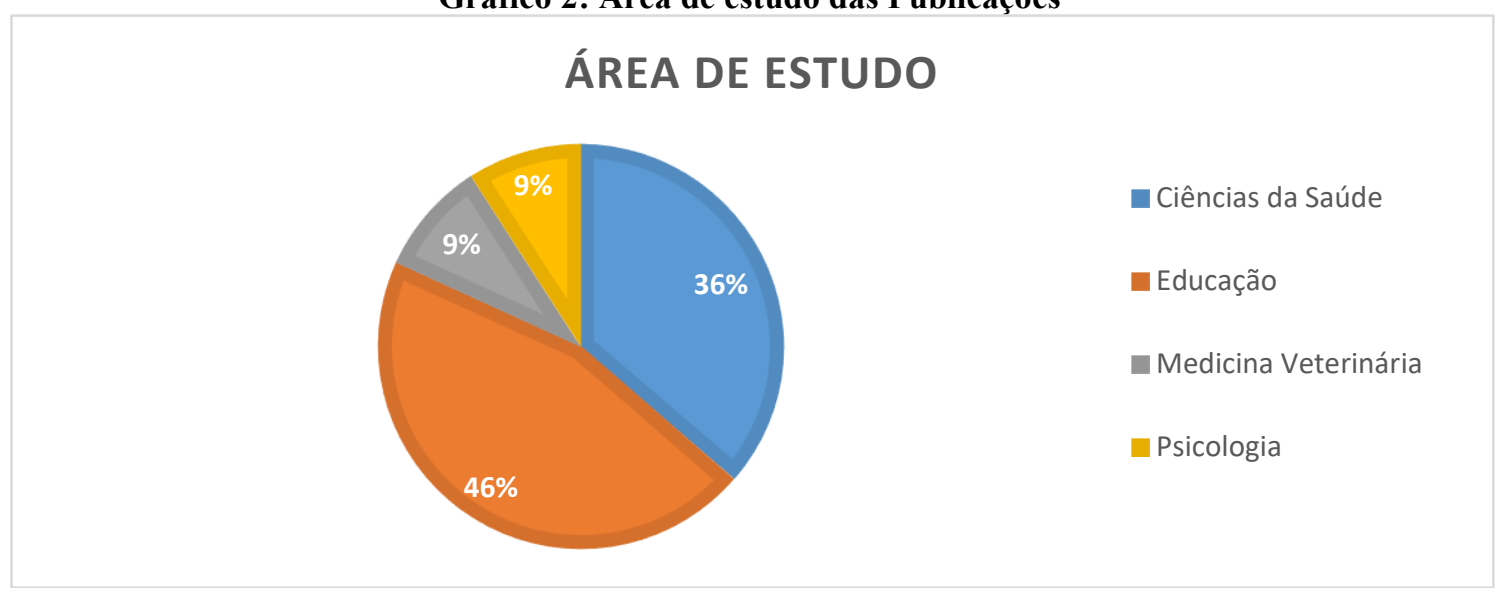

Fonte: Elaborado pelos autores

Quanto ao período em que os trabalhos foram publicados, conforme o Gráfico 3, temos o ano de 2017 com o maior percentual de publicações, $37 \%$ delas, seguido do ano de 2016 com 27\%, 2014 com 18\%, e os anos 2018 e 2015 empatados com apenas 9\% das publicações.

\section{Gráfico 3: Ano das Publicações}

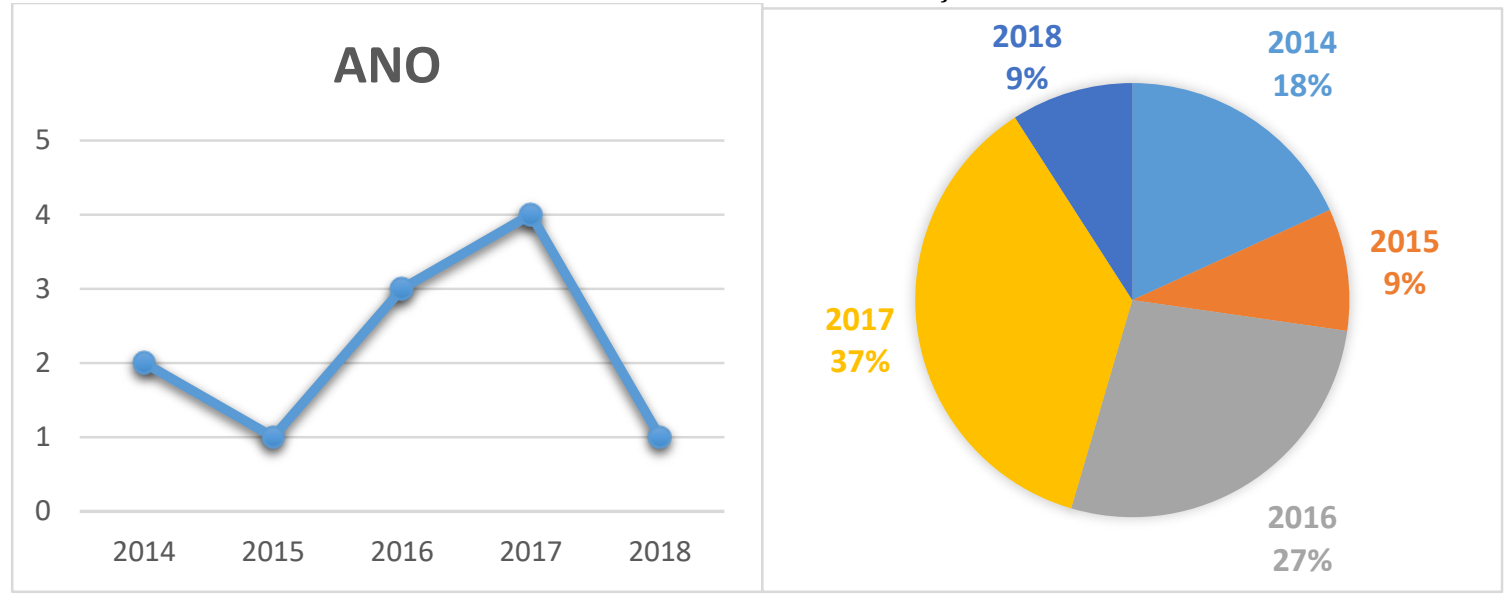

Fonte: Elaborado pelos autores

Quanto aos sujeitos da pesquisa, conforme o Gráfico 4 ilustra, constatou-se que representando a grande maioria, 64\% dos estudos tem como público alvo professores, transpassando as mais diversas áreas, em variados anos, em publicações nacionais, internacionais, bem como em teses, dissertações e artigos. 
VIII Congresso Brasileiro de Informática na Educação (CBIE 2019)

Anais do XXV Workshop de Informática na Escola (WIE 2019)

Gráfico 4: Sujeitos da Pesquisa

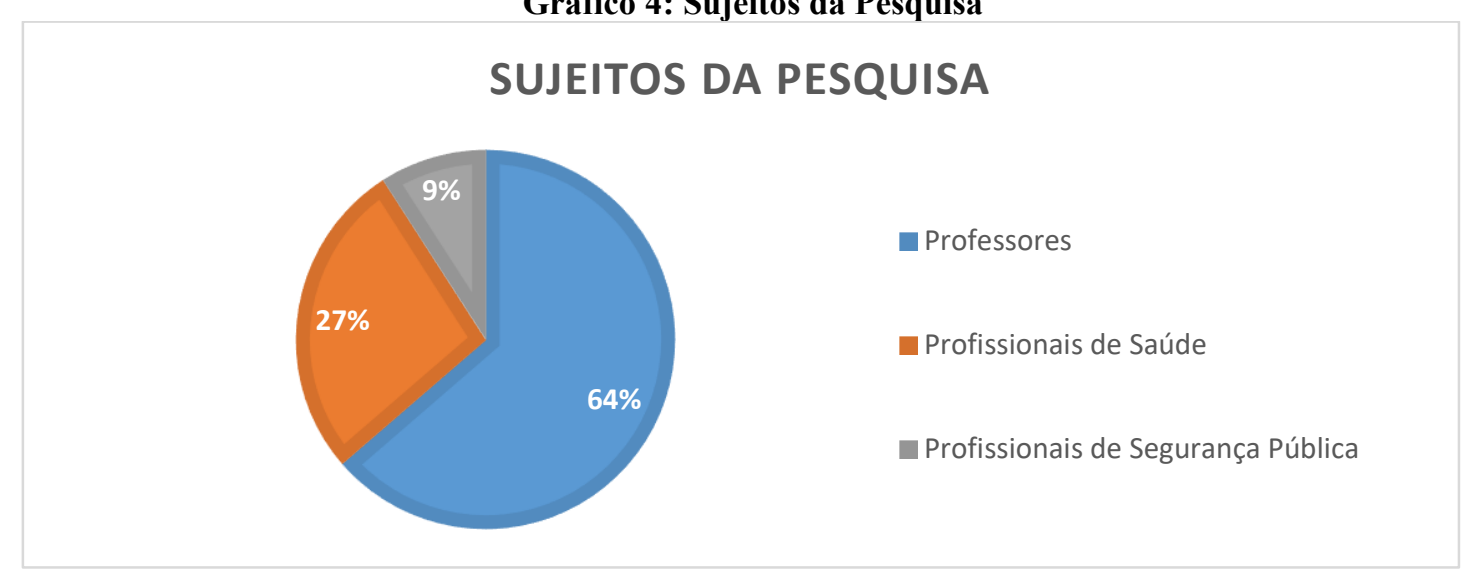

Fonte: Elaborado pelos autores

No que se refere aos procedimentos metodológicos adotados nas publicações relacionadas, conforme é ilustrado no Gráfico 5, obteve-se uma grande variedade de metodologias, desde a dialética de Karl Marx (9\%), estudos descritivos-exploratórios $(9 \%)$, estudos de caso $(18 \%)$, pesquisas participantes $(9 \%)$, pesquisas experimentais $(9 \%)$ e pesquisas-ação (18\%). Constatou-se também que na maioria destes trabalhos $(28 \%)$ não se apresentava explícita a metodologia quanto aos procedimentos utilizados, contudo apresentavam características relacionadas ao método de pesquisa-ação, logo, se considerarmos que se enquadram neste critério, teríamos $46 \%$ dos estudos utilizando a pesquisa-ação como procedimento metodológico.

Gráfico 5: Metodologia utilizada

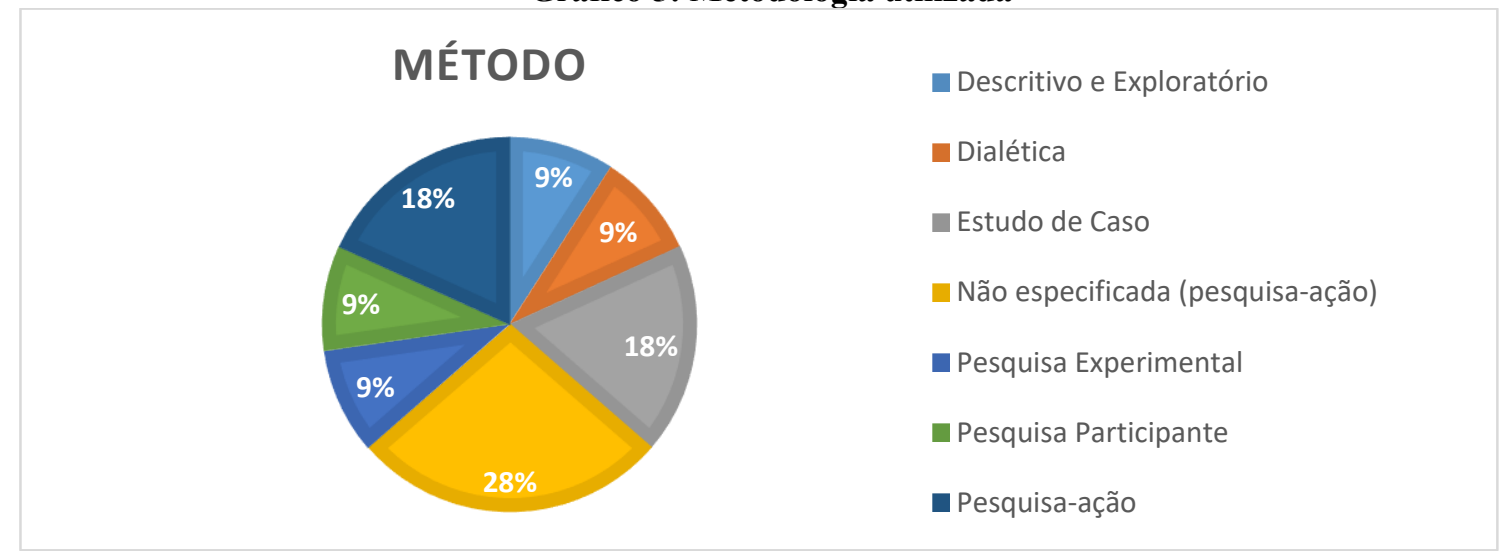

Fonte: Elaborado pelos autores

Outro critério avaliado foi o tipo de plataforma ou ambiente virtual de aprendizagem utilizado como base para os momentos online dos estudos avaliados. Conforme o Gráfico 6 demonstra, 9\% utilizaram a plataforma adaptativa Khan Academy, $18 \%$ não trazem de forma explicita no texto se, e qual plataforma utilizaram, $36 \%$ utilizaram plataformas próprias de suas instituições e 37\% utilizaram a plataforma moodle, tanto em sua versão original quanto em versões customizadas. 
VIII Congresso Brasileiro de Informática na Educação (CBIE 2019)

Anais do XXV Workshop de Informática na Escola (WIE 2019)

Gráfico 6: Plataforma / AVA

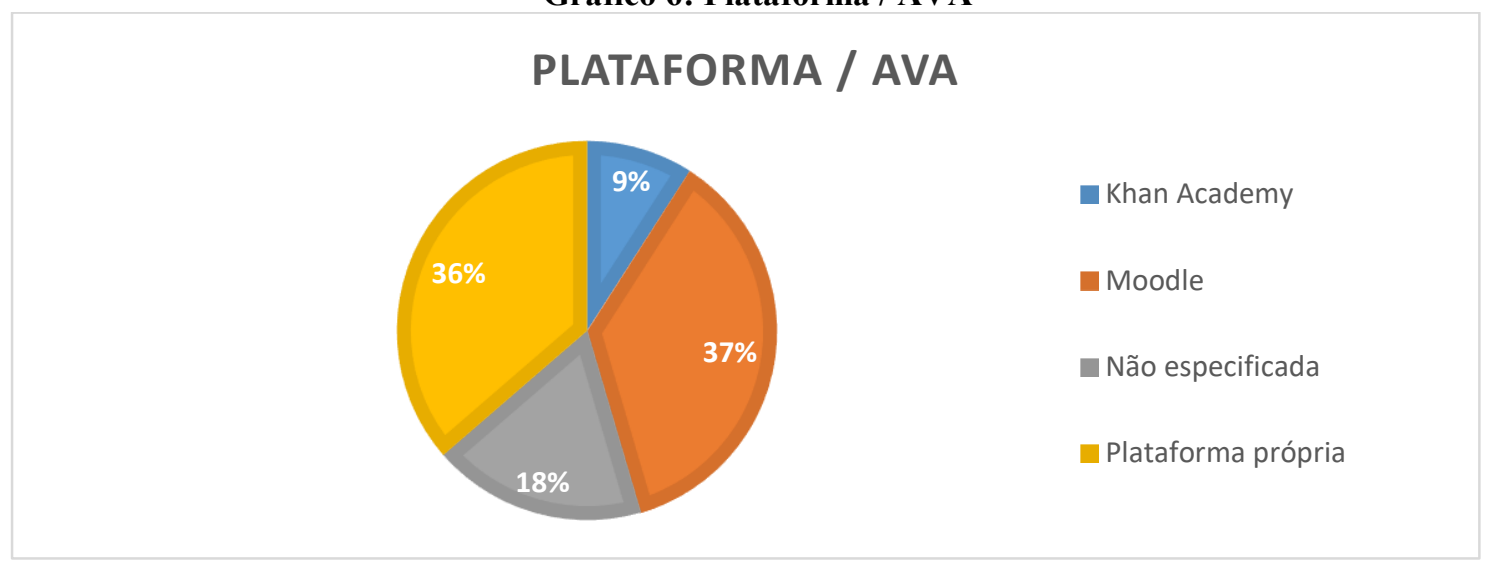

Fonte: Elaborado pelos autores

Por fim, no que se refere ao modelo de ensino híbrido adotado nas pesquisas, conforme o Gráfico 7 demonstra, a expressiva maioria das publicações (82\%) abordam o ensino híbrido de maneira geral sem mencionar as modalidades específicas adotadas, alguns utilizaram os termos "Face to Face + on-line" que caracteriza a existência de momentos presenciais e também de momentos on-line. Dentre os 18\% restantes encontram-se as modalidades: sala de aula invertida e rotação por estações, com $9 \%$ cada. Não foi identificada nenhuma referência aos demais modelos principais definidos na literatura (laboratório rotacional, rotação individual, à la carte e virtual enriquecido).

Gráfico 7: Modelo de Ensino Híbrido

\section{MODELO DE ENSINO HÍBRIDO UTILIZADO}

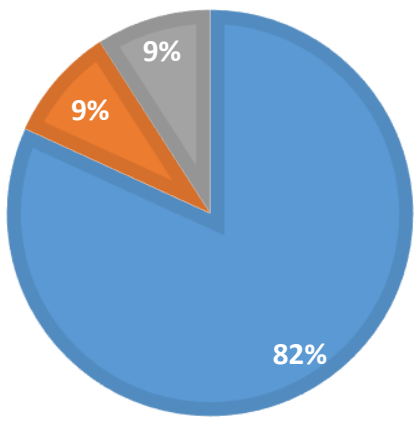

não especificado (face to face + on-line)

notação por estações

- Sala de Aula Invertida

Fonte: Elaborado pelos autores

Apesar da variedade de áreas de estudo, origem e metodologias, quanto aos objetivos dos trabalhos avaliados, constatou-se que todos convergem para o mesmo sentido, pois buscam (identificar, avaliar, compreender) as possíveis contribuições resultantes da aplicação do b-learning em processos de capacitação profissional, seja em capacitações isoladas, módulos de cursos, programas completos de formação, cursos já existentes ou projetados e implementados como projeto experimental ou piloto.

Dentre os critérios avaliados nos estudos estão dados relativos ao processo de construção/execução do curso (eficiência, eficácia, qualidade), bem como critérios relativos aos participantes do processo (professores, alunos, tutores) tais como: percepção, aprendizagem dos sujeitos da pesquisa e desenvolvimento de competências. 
VIII Congresso Brasileiro de Informática na Educação (CBIE 2019)

Anais do XXV Workshop de Informática na Escola (WIE 2019)

Quanto aos resultados dos trabalhos avaliados, todos evidenciam aspectos positivos ao avaliar a aplicação do ensino híbrido em suas pesquisas. Tais resultados estão dentro da expectativa a luz dos benefícios mencionados na literatura acerca da utilização da metodologia. O Quadro 3 contém alguns trechos que merecem destaque.

Quadro 3: Trechos dos resultados

\begin{tabular}{|c|l|}
\hline $\mathbf{A 3}$ & $\begin{array}{l}\text { "Os resultados indicaram que o grupo b-learning experimental mostrou um nível significativamente } \\
\text { mais elevado de conhecimento da abordagem hands-on e satisfação geral com o curso". }\end{array}$ \\
\hline $\mathbf{A 4}$ & "foi possível comprovar a contribuição positiva da formação continuada de docentes" \\
\hline A6 & $\begin{array}{l}\text { "A aprendizagem bimodal alcançou a finalidade de estimular a busca e troca de conhecimentos, } \\
\text { preparar os ingressantes para as atividades que irão assumir, e ainda motivá-los e apoiá-los nesse } \\
\text { ingresso." }\end{array}$ \\
\hline A9 & $\begin{array}{l}\text { "O b-learning foi uma abordagem pedagógica eficaz para esta categoria de profissionais, devido à } \\
\text { necessidade crucial para o treinamento prático para a prática e traduzir conhecimento em habilidades. } \\
\text { Essa abordagem também tinha as vantagens de manter os custos de todo o curso baixo e chegar a um } \\
\text { maior número de participantes, tudo sem interrupção significativa de horários de trabalho." }\end{array}$ \\
\hline A10 & $\begin{array}{l}\text { "Nossos resultados confirmam a eficácia deste modelo e direcionar nossa atenção para estudos mais } \\
\text { aprofundados sobre professores, desenvolvimento profissional para } b \text {-learning em modo blended." }\end{array}$ \\
\hline
\end{tabular}

Fonte: Elaborado pelos autores

Contudo, além dos resultados positivos, em suas conclusões os pesquisadores apontam algumas ressalvas que merecem destaque, sobretudo quanto aos requisitos de seleção dos participantes das formações. Tais requisitos, segundo os pesquisadores influenciam diretamente no aproveitamento em cursos na modalidade b-learning:

- Conhecimento e domínio das tecnologias de informação e comunicação para os momentos on-line;

- Boas habilidades de escrita e redação de texto para o bom desempenho nas tarefas de casa realizadas no AVA;

- As concepções prévias sobre a temática do curso, por questões de nivelamento da turma;

- A importância da organização, disponibilidade e envolvimento com as atividades do curso.

\section{Considerações Finais}

Diante dos resultados obtidos neste mapeamento sistemático da literatura foi possível constatar que mesmo com a limitação de publicações diretamente ligadas a temática pretendida, nos últimos 5 anos foram encontrados trabalhos relevantes em vários níveis de estudo, áreas de atuação e com aplicações e origens variadas a nível mundial.

Foram encontradas publicações em revistas científicas e periódicos, dissertações de mestrado e teses de doutorado. Aplicadas tanto em áreas ligadas à educação conforme o esperado, bem como a outras áreas, com destaque em áreas ligadas a ciências da saúde de um modo geral.

Os trabalhos encontrados apresentaram também origens variadas e com ampla diversidade geográfica, tendo além de publicações de origem nacional, trabalhos de relevância publicados em outros países, distribuídas em quatro dos cinco continentes, podendo refletir a uma realidade a nível mundial. 
VIII Congresso Brasileiro de Informática na Educação (CBIE 2019)

Anais do XXV Workshop de Informática na Escola (WIE 2019)

Ademais, constatou-se que a temática do ensino híbrido é bem difundida no ambiente educacional de um modo geral, tanto nacionalmente quanto internacionalmente, sobretudo na educação formal curricular, desde a educação básica até pós-graduações stricto sensu em nível de mestrado e doutorado. Contudo trata-se de um tema escasso quando o enfoque é aplicado diretamente à capacitação profissional. Além disso, mesmo nos poucos casos em que este enfoque foi dado, se deu de forma genérica na maioria das vezes, desconsiderando a classificações de modelos propostos na literatura.

Portanto o presente MSL, se mostrou oportuno na identificação o estado da arte acerca do ensino híbrido como metodologia aplicada ao processo de capacitação profissional a nível mundial, servindo como etapa importante de uma dissertação de mestrado, bem como base para trabalhos futuros.

\section{Referências}

DERMEVAL, Diego; COELHO, Jorge A. P. de M.; BITTENCOURT, Ig I. Mapeamento Sistemático e Revisão Sistemática da Literatura em Informática na Educação. In: JAQUES, Patrícia Augustin; PIMENTEL, Mariano; SIQUEIRA; Sean; BITTENCOURT, Ig. (Org.) Metodologia de Pesquisa em Informática na Educação: Abordagem Quantitativa de Pesquisa. Porto Alegre: SBC, 2019. (Série Metodologia de Pesquisa em Informática na Educação, v. 2) Disponível em: $<$ https://metodologia.ceie-br.org/livro-2>.

DINIZ, I. J. D; et al. Ensino Híbrido Na Educação Brasileira: Uma Revisão Bibliográfica. In: Anais do III Congresso sobre Tecnologias na Educação. 2018. p. 431-437.

EADBOX.2017. Disponível em <https://eadbox.com/o-que-e-ensino-hibrido/>. Acessado em 05 de junho de 2019.

Horn, M. B. \& Staker, H. (2015). Blended: usando a inovação disruptiva para aprimorar a educação. Porto Alegre: Penso.

KITCHENHAM, Barbara; CHARTERS, Stuart. Guidelines for performing Systematic Literature Reviews in Software Engineering. Technical Report EBSE 2007-001, Keele University and Durham University Joint Report, 2007.

Schiehl, E. P. and Gasparini, I. (2017). Modelos de ensino híbrido: Um mapeamento sistemático da literatura. In Simpósio Brasileiro de Informática na Educação (SBIE).

VALENTE, José Armando. Blended Learning e as mudanças no Ensino Superior: a proposta da sala de aula invertida. Educar em Revista: Dossiê EaD, Curitiba: UFPR, Edição especial n. 4/2014. p. 79-97. Disponível em: $<$ http://ojs.c3sl.ufpr.br/ojs2/index.php/educar>. Acesso em: 17 out. 2017.

MORÁN, J. Mudando a educação com metodologias ativas. In: SOUZA, C. A. de; MORALES, O. E. T. (Orgs.). Convergências midiáticas, educação e cidadania: aproximações jovens. Ponta Grossa, PR: Foca Foto-PROEX/UEPG, 2015, p.15-33. 